\title{
Physical activities in patients with congenital heart disease
}

\begin{abstract}
Young people with congenital heart disease should be encouraged to exercise regularly as this increases functional capacity and decreases myocardial oxygen demand at any level of physical activity. ${ }^{2}$ Supervised exercise plays a major part in cardiac rehabilitation, and patients with congenital heart disease are no exception. ${ }^{23}$ Parents, teachers, and health professionals are nevertheless concerned about the dangers of over-exertion because of the risk of syncope or sudden death. This risk is small ${ }^{4}$ but when it occurs, it has an enormous impact on the attitudes of all concerned. There is little direct evidence that exercise predisposes to death that would otherwise not have occurred, or that withdrawal from sport prolongs life. ${ }^{4-6}$ In a multicentre study, $10 \%$ of sudden deaths occurred during exercise and $58 \%$ at rest. ${ }^{7}$ Many patients who die suddenly have undiagnosed heart disease, ${ }^{5}$ or conditions where prevention is not always possible, such as hypertrophic cardiomyopathy, pulmonary hypertension, or ventricular arrhythmias. ${ }^{89}$ Nevertheless, a few patients are at risk of sudden death which may be provoked by exercise. ${ }^{4}$ It is essential that this risk is minimised, while recognising the benefits of exercise. ${ }^{10}$
\end{abstract}

\section{Clinical assessment}

Most patients with mild or moderate congenital heart disease, including those who have undergone cardiac surgery, have a very low risk of sudden death and require little restriction in physical activities. The decision to limit activity should be based on a comprehensive clinical and risk factor assessment. Regular follow up is essential, as risk may increase with time. Symptoms may be misleading. Children with severe abnormalities may be asymptomatic, and symptoms can be caused by asthma or anxiety. However, $25 \%$ of children who die suddenly have prior presyncopal or syncopal episodes. ${ }^{5}$ Other significant symptoms include chest pain, palpitations, and dizziness. A family history of sudden death is important in patients with hypertrophic cardiomyopathy and prolonged QT syndrome. Assessment also includes review of previous interventions which may indicate potential problems. Clinical examination includes the assessment of the severity of the cardiac lesions, deterioration in ventricular function, and progression of regurgitant or obstructive lesions. The electrocardiogram may show ventricular hypertrophy or strain, and the presence of arrhythmias. Twenty four hour electrocardiographic monitoring is more sensitive in detecting arrhythmias. Echo-Doppler examination is useful in assessing the severity of cardiac lesions and ventricular function.

Exercise testing provides an objective assessment of exercise ability. ${ }^{11}$ It may also demonstrate exerciseinduced arrhythmias or ischaemia in a controlled environment. Breathlessness caused by exercise-induced asthma can be diagnosed by the measurement of peak flow. Exercise testing simulates the increased cardiac output which occurs during pregnancy and may indicate the advisability of pregnancy in some circumstances. Blood pressure monitoring assesses the response to exercise. In patients with cyanosis, monitoring arterial oxygen saturation during exercise may be helpful. A stress echocardiogram may be indicated in patients with the potential for myocardial ischaemia. Electrophysiological studies have not been successful in predicting arrhythmic sudden death. This may be because haemodynamic compromise, together with the arrhythmia, causes sudden death. ${ }^{12}$ Data from cardiac catheterisation are often available, and should be reviewed to assess the severity of residual lesions or pulmonary hypertension.

\section{Recommendations regarding exercise}

It is seldom necessary or even possible to limit the activities of young children. Competitive drive and external pressures are rarely sufficient to push them beyond what they are capable of doing safely. It is often necessary to reassure parents, as this may be an area of great concern. There are a few situations when caution should be advised. When children are learning to swim they should not swim out of their depth, as this prevents them from resting when tired. In cold weather, children run to keep warm. If they have limited effort tolerance, they may not be able to generate sufficient heat. Teachers should be aware of this, and allow children to return inside when they are cold.

Once a young person enters secondary school, pressures to take part in physical activities increase. Sport is classified according to static and dynamic demands, together with the duration and intensity of exertion. Forceful body contact must also be considered, together with the risk of injury if the patient loses consciousness. ${ }^{6}$ The American Heart Association has produced useful recommendations on recreational activities for young patients with heart disease (table). ${ }^{13}$ These, together with the clinical assessment, provide appropriate advice for individual patients. As the AHA document suggests, most young people are able to take part in physical education activities and team sports. More recently, the 26th Bethesda Conference provided comprehensive recommendations for competitive athletes with cardiovascular abnormalities. ${ }^{6}$ Since these apply to competitive sport, they are more stringent than those which are appropriate for recreational exercise.

Aortic stenosis was previously an important cause of sudden death, but such deaths were invariably associated with severe obstruction. ${ }^{7}$ The ability to differentiate between moderate and severe stenosis has caused some of the problems in the past, but cross sectional and Doppler echocardiography has facilitated the detection of severe stenosis. Keane et al ${ }^{14}$ reported sudden death in $6 \%$ of patients, but $26 \%$ had not been seen for 10 years. In another study of 313 patients followed for up to 30 years, ${ }^{15}$ the incidence was $0.3 \%$, indicating that with regular clinical assessment and timely intervention, the risk of sudden death is low. This indicates that mild or moderate aortic 
Recommended physical activity in young patients with heart disease ${ }^{13}$

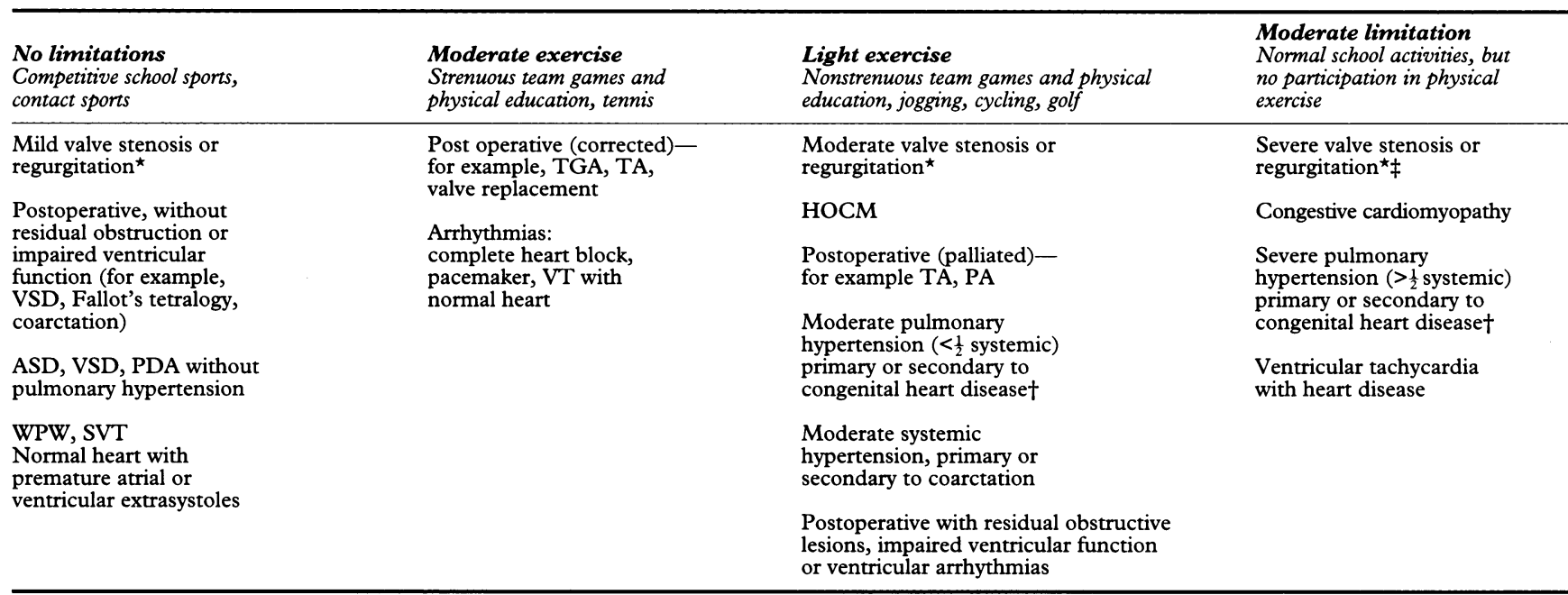

^Aortic stenosis or regurgitation, mitral stenosis or regurgitation, pulmonary stenosis, tricuspid regurgitation (including Ebstein's anomaly).

†For example ASD, VSD, PDA.

AIn patients awaiting intervention.

ASD, atrial septal defect; HOCM, hypertrophic obstructive cardiomyopathy; PA, pulmonary atresia; PDA, patent arterial duct; SVT, supraventricular tachycar-
dia; TA, tricuspid atresia; TGA, transposition of the great arteries; VSD, ventricular septal defect; VT, ventricular tachycardia; WPW, Wolff-Parkinson-White syndia; TA,

stenosis is not a contraindication to physical activities. When the stenosis is approaching a degree at which significant restrictions are indicated, this may be the time to consider intervention.

If restrictions are anticipated as children get older, it is important to give advice for the future, particularly if they show promise. They must understand that they will not be able to take part in some sports at a competitive level, so that their energies can be channelled into less physically demanding sports. The positive aspects of less strenuous and social sports should be emphasised. It is important to help the young person and the family to assess the possible risks in proposed activities. This will depend on the type of sport, together with the competitiveness of the young person and their emotional response to sport. In may also be necessary to assess the pressure from peers, teachers, and parents, and the ability of the patient to pay attention to warning symptoms of breathlessness, fatigue, or lightheadedness. Teachers are unlikely to force a young person with a heart lesion to exercise, but occasionally this information is not passed on. Young people must understand that they should not be pressurised into doing more than they have been advised to do.

There are also dangers from over-protection. Parents should be advised against limiting activities unnecessarily, as this can produce feelings of insecurity or rebellion. ${ }^{3}$ Young people with palliated complex lesions and those with Eisenmenger's syndrome usually live within their limitations. Some need a wheelchair, which may be perceived as an indication of deterioration. However, it allows more mobility for the patient and family and should be encouraged when it becomes necessary.

Exercise promotes physical and mental wellbeing ${ }^{10}$ and provides opportunities for social development. Few patients require significant limitation of recreational activ- ities, but individual assessment allows young people to participate while keeping the risk of adverse effects to a minimum.

Royal Liverpool Children's NHS Trust,

DENISE KITCHINER

Eaton Road

Liverpool L12 AP

1 Fletcher GF, Blair SN, Blumenthal J, Caspersen C, Chaitman B, Epstein $S$, et al. Statement on exercise. Benefits and recommendations of physical activity programs for all Americans. Circulation 1992;86:340-4.

2 Goldberg B, Fripp RR, Lister G, Loke J, Nicholas JA, Talner NS. Effect of physical training on exercise performance of children following surgical repair of congenital heart disease. Pediatrics 1981;68:691-9.

3 Kaplan S, Perloff JK. Exercise and athletics before and after surgery or interventional catheterization. In Perloff JK, Child JS, eds. Congenital heart disease in adults. Philadelphia: WB Saunders, 1991;166-77.

4 Mitchell JH, Maron BJ, Epstein SE. 16th Bethesda Conference: Cardiovascular abnormalities in the athlete: recommendations regarding eligibility for competition. F Am Coll Cardiol 1985;6:1186-232.

5 Maron BJ, Epstein SE, Roberts WC. Causes of sudden death in competitive athletes. F Am Coll Cardiol 1986;7:204-14.

6 Maron BJ, Mitchell JH. 26th Bethesda Conference: Cardiovascular abnormalities in the athlete: revised eligibility recommendations for competitive athletes with cardiovascular abnormalities. $\mathcal{F}$ Am Coll Cardiol 1994; 24:845-99.

7 Lambert EC, Menon VA, Wagner HR, Vlad P. Sudden unexpected death from cardiovascular disease in children. Am $\mathcal{F}$ Cardiol 1974;34:89-96.

8 Garson A, McNamara DG. Sudden death in a pediatric cardiology population, 1958 to 1983: relation to prior arrhythmias. $\mathcal{F} \mathrm{Am}$ Coll Cardiol 1985; tion, 1958 to

9 McNamara DG. Special problems in infants, children and young adults, including postoperative sudden death: summary. $\mathcal{F}$ Am Coll Cardiol 1985;

10 Trippe H. Children and sport. BMF 1996;312:199-200.

11 American College of Sports Medicine. Guidelines for exercise testing and prescription. 4th ed. Philadelphia: Lea \& Febiger, 1991;87.

12 Deanfield J, Camm J, Macartney F, Cartwright T, Douglas J, Drew J, et al. Arrhythmias and late mortality after Mustard and Senning operation for transposition of the great arteries: an eight year prospective study. $\mathcal{F}$ Thorac Cardiovasc Surg 1988;96:569-76.

13 Gutgesell HP, Gessner IH, Vetter VL, Yabek SM, Norton JB. Recreationa and occupational recommendations for young patients with heart disease. Circulation 1986;74:1195A-8A.

14 Keane JF, Driscoll DJ, Gersony WM, Hayes CJ, Kidd L, O'Fallon WM, et al. Second natural history study of congenital heart defects. Results of treatment of patients with aortic valvar stenosis. Circulation 1993;87 suppl I:1 1-27.

15 Kitchiner DJ, Jackson M, Walsh K, Peart I, Arnold R. The incidence and prognosis of congenital aortic valve stenosis; Liverpool (1960-1990). $B r$ Heart f 1993;69:71-9. 